\title{
Parents' and Teachers' Beliefs About Adolescents: Effects of Sex and Experience
}

\author{
Christy Miller Buchanan, ${ }^{1}$ Jacquelynne S. Eccles, ${ }^{2}$ Constance Flanagan, ${ }^{3}$ \\ Carol Midgley, ${ }^{4}$ Harriet Feldlaufer, ${ }^{5}$ and Rena D. Harold ${ }^{6}$
}

Received August 4, 1988; accepted November 20, 1989

Three studies examine beliefs that parents and teachers have about adolescents. A distinction is made between category-based beliefs (concerning adolescents as a group) and target-based beliefs (concerning individual adoles-

Portions of this paper were presented at the 1987 biennial meetings of the Society for Research in Child Development. This research was made possible by grants from the National Institute of Mental Health (MH31724-04, -05) to Jacquelynne S. Eccles, and the National Institute of Child Health and Human Development (HD17296-01, -02, -03,S1) to Jacquelynne S. Eccles. ${ }^{1}$ Research Associate, Family Studies Center, Building 460, Stanford University, Stanford, California 94305. Received Ph.D. in psychology from The University of Michigan. Research interests: adolescent development, effects of pubertal development on social development, hormones and behavior in early adolescence, and family processes. To whom correspondence should be addressed.

${ }^{2}$ Professor, Department of Psychology, The University of Colorado, Boulder, Colorado 80309, and The University of Michigan, Ann Arbor, Michigan 48109. Currently on leave from The University of Michigan. Received Ph.D. in psychology from the University of California at Los Angeles. Research interests: development of self-concept, subjective task value, interests, and activity preferences, especially during early and middle adolescence. Dr. Eccles is also investigating the impact of school and family experiences on these constructs.

${ }^{3}$ Assistant Professor, The University of Michigan, Dearborn, Michigan. Received Ph.D. in psychology from The University of Michigan. Research interests: the impact of family stress on adolescent development and family decision-making practices.

${ }^{4}$ Research Coordinator, Leadership and Learning Laboratory, School of Education, The University of Michigan, Ann Arbor, Michigan 48109. Received Ph.D. in education from The University of Michigan. Research interests: adolescent development, middle years education, teacher beliefs, and classroom processes.

${ }^{5}$ Associate Education Consultant, Connecticut State Department of Education, Hartford, Connecticut $\mathbf{0 6 1 4 5}$. Received M. A. in education from the University of Michigan. Research interests: adolescent development, classroom environments, and supporting beginning teachers. ${ }^{6}$ Assistant Professor, Michigan State University, Lansing, Michigan. Received Ph.D. in social work and psychology from The University of Michigan. Research interests: family processes and development. 
cents). In Study 1, 90 late elementary and junior high school teachers indicated degree of agreement with a set of category-based statements about adolescents. Parents of early adolescents in Study $2(\mathrm{~N}=1272)$ responded to category-and target-based statements. Study 3 compares the responses of teachers in Study 1 and parents in Study 2. Both teachers and parents endorsed beliefs that adolescence is difficult, and that adults can have an impact. Compared to fathers, mothers believed more in difficulty and in the negative effects of biological change on behavior. Parents of daughters believed adolescence is more difficult than parents of sons. Among teachers, amount of experience with adolescents was positively associated with the belief that adolescence is a difficult period of life. For parents, the effect of amount of experience was mixed. Experience had a greater impact on the categorybased beliefs of teachers than parents. Possible influences on the origins and modification of beliefs are discussed.

\section{INTRODUCTION}

A growing literature addresses the issue of parents' and other adults' beliefs about child development (see Goodnow, 1988). Such research is interesting for several reasons. First, it provides information about cognitive processes beyond childhood (Goodnow, 1984). Second, it will increase our understanding of parents' expectations for and interpretations of their children's behavior (Eccles-Parsons et al., 1982), and consequently may provide insights into the ways adults interact with children (e.g., Dix, 1985). For example, Jacobs (1986) and Eccles and Jacobs (1986) have found that parents' general gender role stereotypes regarding competence in various academic and nonacademic domains affect parents' estimates of their own children's abilities in these domains, and help explain the sex differentiated expectations parents have for their children's performance. This work suggests that parents' and teachers' beliefs regarding important developmental periods might influence their reactions to children at these stages.

Adolescence is a developmental period for which there are widely held cultural myths that could lead to stereotypic perceptions both of adolescents as a group and of specific individuals. Adolescence is seen as a troubled time, a time of fluctuating hormones and biologically determined drives over which there is little control. The typical adolescent is assumed to be prone to mood swings, emotionality, and rebelliousness (e.g., "Teen Rage," 1987). Despite the growing body of empirical evidence refuting such beliefs, "storm and stress" notions persist, as evidenced by the continuing portrayal of adolescents as neurotic, semidelinquent, and/or criminal in movies, television, books, and the news media by both writers of fiction and prominent professionals (e.g., "The Age of Insolence: Those Terrible Teens," published in 
1983 by R. Coles; cited by Petersen, 1985). Given people's tendency to overgeneralize information from deviant samples (Bandura, 1964; Falchikov, 1986; Porteous and Colston, 1980), such portrayals are likely to reinforce preexisting stereotypes.

This paper explores the beliefs that parents and teachers hold about adolescence. It focuses on the distinction between category-based beliefs (beliefs regarding a social category such as adolescence) and target-based beliefs (beliefs regarding specific individuals such as one's own child), and assesses the impact of experience on both sets of beliefs.

Few studies directly assess adults' beliefs about adolescence, and those that do tend to sample health professionals and undergraduate and graduate students. Health professionals tend to endorse the storm and stress view of adolescence (Lavigne, 1977; Offer et al., 1981), and do so to a greater extent than both graduate psychology students and adolescents themselves (Offer et al., 1981), although college-aged adolescents also tend to endorse storm and stress notions, especially concerning identity development and problems in parent-child relationships (Holmbeck and Hill, 1988). Medical personnel also believe adolescent problems are more attributable to "developmental stage" than problems of other age groups (Beck et al., 1985) and that adolescents will "outgrow" their psychiatric problems (Lavigne, 1977).

We know very little about teachers' and parents' views of adolescence. On the one hand, in a poll taken in 1965 many teachers expected "great emotional disturbance" and even a "complete personality change" during adolescence (Friedman, 1975, p. 523). On the other hand, there is good reason to believe parents and teachers of adolescents may not endorse generalized negative views of adolescence. Unlike mental health workers, who are exposed to troubled adolescents, parents and teachers spend most of their time with more typical adolescents. For most children, adolescence is a relatively stable and harmonious period, no more characterized by psychiatric disorder than other developmental periods (Bandura and Walters, 1959; Bengtson, 1970; Douvan and Adelson, 1966; Elkin and Westley, 1955; Epperson, 1964; Offer, 1969; Rutter et al., 1976). Although there is some conflict with parents, it tends to be over mundane, domestic issues such as neatness, curfews, proper dress, and taste in music, rather than more fundamental values (see Montemayor, 1983). If daily experience can modify general stereotypic beliefs, then parents and teachers who have prolonged and frequent contact with the more typical adolescent should hold less stereotypic views of adolescence than mental health professionals.

Further, Knight (1985) argues that a critical aspect of adult coping is the belief that bad situations can be altered. She portrays parents as "developmental optimists" who need to see bad situations as changeable in order to continue their task of parenting. Thus, even if parents and teachers do 
believe adolescence is a difficult time, they may also believe the difficulty is not inevitable, and they, or others, can have a positive impact on adolescent children. This suggests the importance of a distinction between beliefs about the types of problems adolescents are likely to experience and beliefs about the potential impact of adult support. Knight's work suggests that even if parents and teachers do endorse stereotypic beliefs about the problems of adolescence they should also endorse an optimistic view about their role and the ultimate developmental trajectory.

But does consistent contact with adolescents modify beliefs, and if so, under what conditions and on what indicators? To answer these questions we need to distinguish between general category-based beliefs and more specific target-based beliefs. Social psychological studies of stereotypes document both the importance of this distinction and the difficulty of getting transfer across the two levels of beliefs. For our purposes, this distinction is critical in predicting which beliefs are likely to be influenced by experience.

The general beliefs parents have about developmental processes are acquired through both cultural transmission and personal experience (Goodnow et al., 1986). For example, if strong culturally based stereotypic notions exist about milestones in development, or about behavior at certain ages, parents' beliefs should reflect such category-based stereotypes. In this culture, strong stereotypes certainly exist about adolescence, and these should be reflected in both parents' and teachers' category-based beliefs about adolescents.

But adults' beliefs are also shaped by experiences they have had either growing up or with their own or other children. Goodnow et al. (1986) refer to the merging of cultural stereotypes and personal experience as "reality testing." To the extent that reality does not match cultural beliefs or stereotypes, general beliefs may change as a function of experience with the target group. Consequently, since parents and teachers have first-hand experience with "normal" adolescents, they may hold less stereotyped category-based beliefs about adolescents. Alternatively, it is possible that general category-based stereotypes remain stable as each discrepant case is discounted as an exception, especially given the number of stereotype-consistent examples provided by the media. If so, experience might have a stronger impact on expectations for specific individuals (i.e., target-based beliefs) than on more general stereotypes. For example, most of the evidence collected by Goodnow, Knight, and others (e.g., Feldman and Yirmiya, 1986; Goodnow et al., 1981, 1984; Knight, 1983, as cited by Goodnow, 1984) regarding parental ideas about development at younger ages suggests that cultural transmission is a very powerful influence. Aspects of personal experience such as socioeconomic status, sex of child, or birth order of child appear to have amazingly little impact on parents' general beliefs in these studies. At the same time, Eccles-Parsons et al. (1982) found a strong relationship between specific chil- 
dren's performance in school and the specific future performance expectations that their parents held for them. Similarly, Knight (1983, as cited in Goodnow, 1984) reported evidence that could reflect the effects of personal experience on parental target-based beliefs: mothers felt they had more influence over their own child's social behaviors than fathers. Although such parental sex differences may simply reflect sex-related cultural stereotypes about mothers' and fathers' influence on their children, they may also be indicative of different experiences that mothers and fathers have with their children.

Although theory and evidence suggest that experience with specific individuals may influence target-based beliefs more than category-based beliefs, repeated experience with members of the category could be expected to influence category-based beliefs as well. Consequently, one might expect that experience would be more strongly related to category-based beliefs in teachers of adolescent students than to the same beliefs in parents.

If indeed personal experience can modify beliefs, what kinds of effects might it have? First, it might be expected to influence the degree to which a stereotype is endorsed. For example, if adolescents are not as troubled as stereotypes would suggest, parents who have had experience with at least one adolescent should hold less extreme stereotypes than parents who have not had this experience. Additionally, parents' expectations for their own children (target-based beliefs) should be more influenced by experience than their more general beliefs about adolescents as a group (category-based beliefs). Although they did not examine parental expectations, Cohen et al. (1986) did find that parental anxiety about the onset of adolescence was lower among parents of later-borns than parents of firstborns, suggesting that experience may change one's expectations for this time. Second, Goodnow et al. (1986) suggest that "the most promising signs of difference in ideas related to variations in experience lie in the greater differentiation of ideas with experience" (p. 302). This suggests that the beliefs of persons who have different experiences with adolescents may differ in their variability more than their mean level. To the extent that stereotypes are the primary source of information underlying one's beliefs, variance of the responses from a relatively homogeneous sample of people should be low. Experience provides a new source of information; a source that is likely to be more variable across individuals or families. Consequently, variance should be higher among people with more exposure to adolescents. Following our earlier reasoning, experience should also have a stronger influence on the variability of target-based than categorybased beliefs.

Until now, we have not explicitly defined "experience." It is possible to conceptualize experience in various ways, including (1) the amount of exposure one has to adolescents as individuals or as a group; and (2) the quality of one's interaction with adolescents, or the role one plays with them. Since 
mothers and fathers differ on both of these, sex of parent can be used as one indication of differential experience. On the one hand, mothers spend more actual time with their children than fathers, especially before adolescence (Montemayor, 1982, 1986; Timmer et al., 1985); thus, like individuals who have exposure to one or more adolescents compared to those who do not, mothers may be more inclined to take into account individual exceptions to general stereotypes. On the other hand, there are qualitative differences in the relationships mothers and fathers have with their children that may affect their expectations for the adolescent period. Lamb (1981), for example, reported that during the early childhood years, fathers act more as playmates while mothers act more as caretakers and nurturers to their children. Similarly, based on a study of parent-adolescent interactions, Youniss and Smollar (1985) contend that mothers and fathers "have separate but conjunctive functions within the family system" (p. 82). Fathers tend to play an instrumental function, focusing on issues of performance and being recruited into communication over personal matters only when special advice is needed. Mothers, on the other hand, who fulfill both instrumental and expressive functions in the family system, are more aware of and responsible for the everyday details of adolescent life. Mothers are more likely to monitor their adolescent's behavior, acting as advisors and disciplinarians. They tend to empathize more often with their children's experience and act not only as authorities but also as confidants. Thus, mothers may be more aware than fathers of the "troubles" their adolescent children are having.

Other work has suggested that conflict in adolescence is more common between adolescents and their mothers than adolescents and their fathers (Montemayor, 1982; Montemayor and Hanson, 1985), and that mothers perceive conflict with adolescents differently than fathers (Hill and Holmbeck, 1987a). According to Hill and Holmbeck (1987a), mothers are more likely than fathers to associate disagreements over rules with oppositionalism on the part of the child. These authors suggest that this is due to the particular role of the mother in maintaining family harmony and connectedness. Thus, the qualitative role played by mothers would lead one to expect something different from their quantitative one: whereas more time spent with preadolescent and adolescent children should lead to more discounting of stereotypes, more awareness of and sensitivity to instances of difficulty may in fact lead to a greater endorsement of negative expectations typical of adolescent stereotypes.

Experience can also be conceptualized in terms of the amount of one's previous exposure to other adolescents. For teachers, this type of experience can be measured by the number of years one has been teaching adolescents. For parents, this can be measured by birth order of a target child (parents whose adolescent, or preadolescent, child is first- or only-born have had less 
experience with adolescents than other parents). In both cases, one would expect adults with more experience to have either less stereotyped beliefs or more variable beliefs, or both.

Furthermore, since parents' experiences are with individual children while teachers' experiences are more with adolescents as groups, we would expect "experience" operationalized this way to have a greater impact on teachers' category-based beliefs than on parents' category-based beliefs. As before, we would expect parents' experience to have more impact on their target-based beliefs than on their category-based beliefs.

Target-based beliefs regarding early adolescent behavior should also be affected by the sex of one's child. Girls enter puberty at an earlier age than boys and have more visible external physical signs of puberty early in adolescent development. Thus, at any specific age during the early adolescent period, girls will seem more "adolescent." If stereotypes about early adolescent behavior affect target-based beliefs, or if there is a kernel of truth in these stereotypes, then parents should make more stereotyped ratings of girls than of same-aged boys for children in the very beginning of early adolescent development. The importance of biological explanations for early adolescent behavior should also be especially marked for girls for two reasons. First, girls at this age show more marked physical changes than boys. Second, pubertal development in girls implies the onset of menstrual cycles, a separate biological event for which there are also widely held stereotypes regarding affects and behaviors such as moodiness, irritability, and sadness.

There is also some evidence that although mothers experience conflict with both adolescent sons and daughters, conflict with daughters is more common (Montemayor, 1982) and more likely to persist throughout puberty, especially if the girl is an early maturer (Hill et al., 1985; Steinberg, 1987). Hill and Holmbeck (1987b) found that pubertal maturation was positively related to sons' reports of maternal acceptance and negatively related to daughters' perceptions of both maternal and paternal acceptance. Perhaps parents are more accepting and adaptive regarding a son's maturation than a daughter's. For daughters, parents may be more concerned about dating and sexual involvement that comes with reproductive maturity (Hill et al., 1985). Thus, given girls' particular biological development and the stereotypes associated with it, coupled with parents' reaction to girls' vs. boys' development, we would expect differing target-based beliefs about adolescence among parents of girls and parents of sons.

In summary, we hypothesize the following:

1. Teachers and parents will endorse the idea that adolescence is a difficult time as well as the belief that adults can intervene, or have an impact, during this time. 
2. In general, parents will endorse stereotyped category-based beliefs more strongly than stereotyped target-based beliefs, since target-based beliefs are more likely to depend on characteristics of the target child.

3. Due to the fact that they spend more time and often have more intimate relationships with their children, mothers are expected to be more variable in their beliefs about adolescents. Mothers may also be less stereotyped than fathers, since the increased time spent with their children should give them more opportunities to see exceptions to stereotypes. In addition, because mothers play a more central socialization role with children, they should hold more optimistic views regarding the future course of their children's development. However, mothers may actually indicate more stereotypes in the sense of expressing more belief in difficulty and conflict due to the unique nature of the mother's role. It is not clear which of these differences between mothers and fathers will take precedence. However, because one's experience with individual adolescents will be more likely to affect beliefs about specific individuals than about adolescents in general, we expect to see stronger and more frequent sex of parent differences (in terms of both mean and variance measures) on targetbased beliefs than category-based beliefs.

4. Parents reporting on later-born adolescents will be less stereotyped in their view of adolescence than parents reporting on firstborn or only-child adolescents. Parents with more experience are also expected to exhibit more variability in their beliefs about adolescence than parents with less experience. Finally, the differences between parents of first- and later-borns will be stronger for target-based than categorybased beliefs.

5. Parents reporting on early adolescent daughters will make more stereotyped target-based ratings than parents reporting on sons of the same age. Parents' category-based beliefs should be relatively unaffected by the sex of their child with one exception: parents, especially mothers, of daughters should be sensitized to the biological explanations of adolescent behavior because of the stereotypes regarding menstrual cycles. This may make them more likely to endorse stereotypical beliefs about difficulty during adolescence and the importance of biological changes at this time.

6. The longer teachers have been teaching adolescents, the less stereotyped and more variable their category-based beliefs will be.

7. Since male and female teachers play more similar roles than mothers and fathers, and since the time spent with adolescents is more similar for male and female teachers than for mothers and fathers, we expect to find stronger sex differences between male and female parents than between male and female teachers. 
8. Since teachers are exposed to adolescents as a group more than parents (whose experience is more individualized), amount of experience is expected to have a greater impact on teachers' category-based beliefs than parents' category-based beliefs.

\section{METHOD OVERVIEW}

The findings from two related studies are reported in this paper. These studies are part of a longitudinal study (the Transitions in Early Adolescence study directed by J. S. Eccles) investigating the impact of changes in the classroom and family environment on early adolescents' self- and achievementrelated motives, beliefs, values, and behaviors. The Transitions study consists of four waves of data collection - in the fall and spring of the children's sixth- and seventh-grade year. Student and teacher questionnaires were administered in math classrooms; parent questionnaires were mailed to the home.

Since there were no established scales assessing stereotypes about the adolescent period, new items were developed for the current study. In keeping with our earlier discussion, items tapped beliefs regarding both typical behaviors associated with adolescence as well as the likely effectiveness of adults in helping children in this age range.

Specific details about the samples and methods are included in the description of each study.

\section{STUDY 1: TEACHERS' BELIEFS ABOUT EARLY ADOLESCENCE}

\section{Method}

\section{Sample}

Findings reported here are based on data collected via questionnaires given to teachers in the fall of 1984 at Wave 3 of the Transitions in Early Adolescence study. (Elementary school teachers who participated at Waves 1 and 2 did not complete the stereotypes measure, and thus are not included in this report. Ten teachers who replaced Wave 3 teachers at Wave 4 [spring of 1984] are included in this sample.) All eligible Year 2 mathematics teachers in participating schools agreed to join the study. These teachers were asked to return their completed questionnaires in a mailer provided by the researchers; all but six returned the questionnaire. The final sample size was 90 . Sixtyfour of these teachers taught math in departmentalized junior high schools, 17 taught math in self-contained classrooms in junior high schools, and 9 
taught sixth-grade math in elementary schools. Of the 90 teachers, 46 were female.

\section{Measures}

As part of a longer questionnaire, teachers were asked nine questions assessing their category-based beliefs about early adolescence. These items are listed in Table I. Each question used a 5-point Likert-type scale anchored with (1) Strongly Disagree to (5) Strongly Agree. In addition, to assess experience with adolescents, teachers were asked how long they had been teach-

Table I. Means and Standard Deviations of Category-Based Beliefs in Two Samples ${ }^{a}$

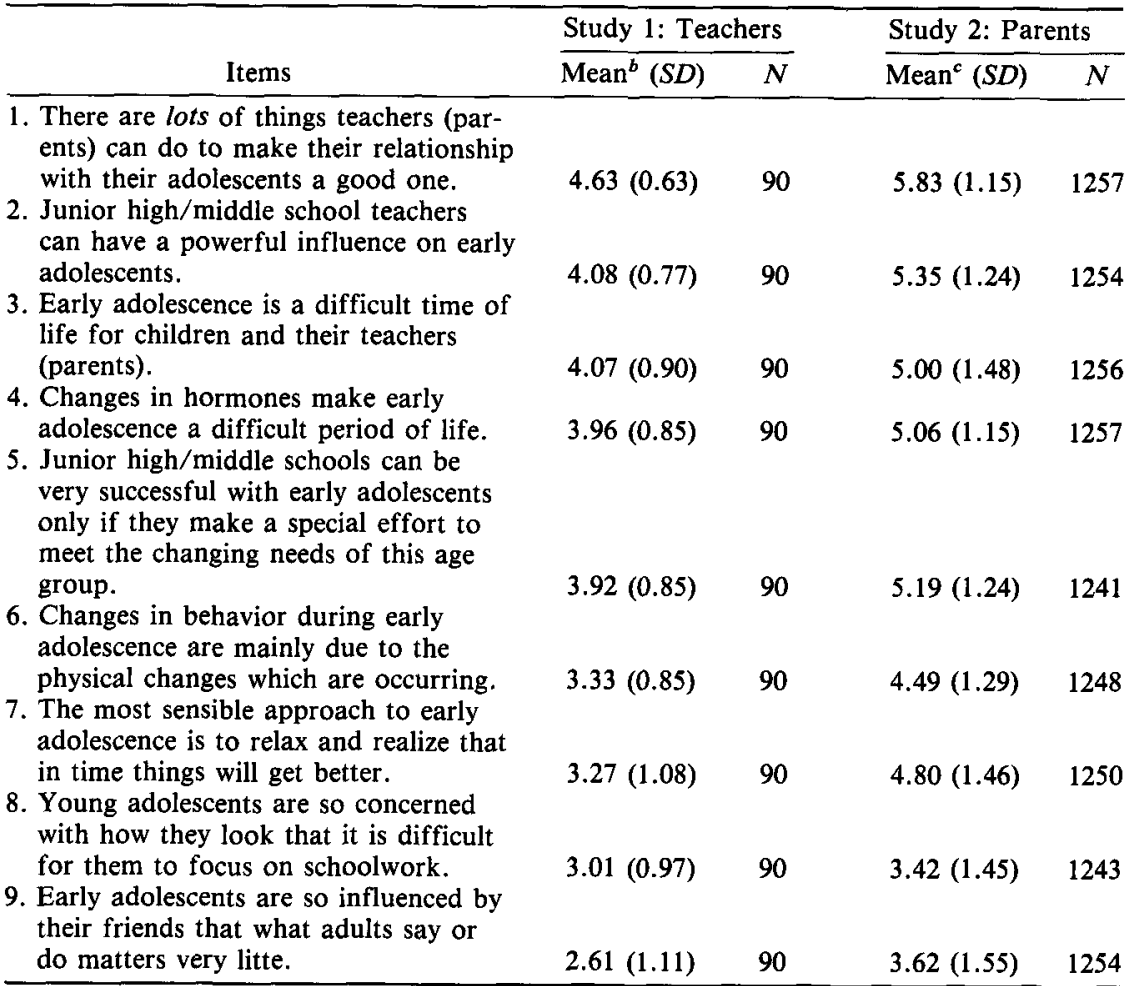

${ }^{a}$ For parents, the introductory stem read as follows: "Children around the age of your son/daughter are sometimes called 'early adolescents.' We are interested in your opinions about this time of life. Use the scale below to rate each of the following (strongly disagree to strongly agree)." For teachers, the stem was as follows: "Much has been written about the stage of life called 'early adolescence.' We are especially interested in the opinions of professionals and parents who work with young adolescents. Please indicate your opinion about each statement by circling the appropriate response."

${ }^{b}$ On a 5-point scale.

${ }^{c}$ On a 7 -point scale. 
ing math at their current grade level. Teachers were not asked to report target-based beliefs since, unlike parents of adolescents, there is no one target adolescent that is appropriate for teachers.

\section{Analyses}

Multivariate profile analyses (a form of multivariate analysis of variance) and univariate analyses of variance were performed to detect mean differences in beliefs depending on sex of the teacher and sex by item interactions. Since years teaching math at the junior high school level ranged from 1 to 27 years, correlations were used to examine the relation between experience teaching adolescents and category-based beliefs. To test whether teachers who had been teaching longer were more variable in their beliefs, teachers were grouped into those who had been teaching one or two years $(N=37)$, and those who had taught three or more years $(N=53)$. The $F$ test for homogeneity of variance was used to examine whether more experience was associated with greater variability of beliefs. The bracketed version of teacher experience was also used in multivariate profile analysis in order to examine experience by item interactions.

\section{Results}

Multivariate profile analyses revealed significant differences between item means for teachers $(F[8,81]=41.1, p=.000)$. Table I contains the means and standard deviations for each item. In general, junior high school teachers endorsed most highly items related to the potential positive influence

Table II. Teacher Category-Based Belief Composites: Items, Factor Loadings, and Reliability Factor I: Difficult stage, alpha $=.70$

.67 Early adolescence is a difficult time of life for students and their teachers.

.47 The most sensible approach to early adolescence is to relax and realize that in time things will get better.

.69 Changes in hormones make early adolescence a difficult period of life.

.70 Young adolescents are so concerned with how they look that it is difficult for them to focus on schoolwork.

.45 Changes in behavior during early adolescence are mainly due to physical changes which are occurring.

Factor 2: Adults can influence, alpha $=.58$

-.49 Early adolescents are so influenced by their friends that what adults say or do matters very little.

.49 There are lots of things parents can do to make their relations with their adolescents a good one.

.80 Middle/junior high school teachers can have a powerful influence on the early adolescent.

.44 Middle/junior high schools can be very successful with early adolescents only if they make a special effort to meet the changing needs of this age group. 
adults can have on early adolescents (Items 1,2, and 5 in Table I), and items indicating that early adolescence is a difficult period (Item 3 ), with hormones being seen as a more important cause of this difficulty (Item 4) than physical or social changes (Items 6,8 , and 9).

A principal components analysis of the nine items measuring categorybased beliefs about early adolescence yielded two factors with eigenvalues greater than one. These two factors were rotated using an oblique solution, because we had no reason to assume that the factors would be uncorrelated. Two distinct factors were identified (see Table II for dimensionality, factor loadings, and reliability). One factor assesses the belief that early adolescence is a difficult time (Difficult Stage); the other assesses the belief that adults can have a positive impact on early adolescencts (Adults Can Influence). Composites reflecting these two sets of beliefs were created by taking the mean of the item scores. The two composites were not highly correlated $(r=-.17)$, indicating that although mean levels of endorsement on the two composites are relatively high, it is not necessarily the same teachers who are endorsing both.

As predicted, no significant sex differences in mean level of beliefs were found at the composite level. There were also no differences in variability by teacher sex on any of the items. Multivariate profile analyses using the sets of items in each composite also revealed no interactions between teacher sex or experience and particular category-based items.

Correlations were used to test the relationship between the nonbracketed version of teacher experience and category-based beliefs. There was a significant relationship between the belief that adolescence is a difficult stage and the number of years a teacher had been teaching at the junior high school level $(r=.29, p<.03)$. Contrary to what we predicted, teachers with more years of experience held a more extreme view of this developmental period. The correlation between teacher experience and the belief that adults can have an influence on adolescents was not significant $(r=.003)$. Also, contrary to our prediction, the $F$ test for homogeneity of variance on the belief items indicated that variance did not differ by experience groups.

\section{STUDY 2: PARENTS' BELIEFS AND EXPECTATIONS CONCERNING EARLY ADOLESCENCE}

\section{Method}

\section{Sample}

Parents were recruited through a letter distributed to students in sixthgrade math classrooms. The sample used for the study reported here was 
a subset of the total sample of parents who participated. The subsample consisted of 636 intact mother-father pairs who participated in the study at both Waves 1 and 3 . A total of 293 pairs $(46 \%)$ were parents of early adolescent daughters and 343 pairs $(54 \%)$ were parents of early adolescent sons. A total of $254(40 \%)$ of these sets of parents were novices (i.e., their oldest or only child was in the study); the other $382(60 \%)$ sets of parents were experienced (i.e., their participating child was a later-born child). Ninety-four percent of the families had an annual income over $\$ 20,000$. Seventy-five percent of the mothers and $59 \%$ of the fathers were high school graduates. Twentyone percent of the mothers and $36 \%$ of the fathers were college graduates. Parents reported on their children's ethnicity; over $97 \%$ of the children of families in this sample were white.

\section{Measures}

Questionnaires with stamped return envelopes were mailed to participating parents. Mothers and fathers completed questionnaires independently. Eleven target-based items, assessed at Wave 1, tapped parents' expectations for their own child's behavior when $\mathrm{s} /$ he reached junior high school (see Table III). Response options for each statement used a 7-point Likert-type scale anchored with (1) Strongly Disagree and (7) Strongly Agree. The nine category-based questions used with teachers (see Table I) were also given to the parents at Wave 3, with wording changed from "teachers" to "parents" where appropriate. These items were introduced with the statement, "Children at the age of your son/daughter are sometimes called 'early adolescents.' We are interested in your opinions about this time of life." Response options were the same as those described for target-based beliefs.

Table III. Means and Standard Deviations of Target-Based Beliefs

\begin{tabular}{llc}
\hline $\begin{array}{l}\text { I expect that when my child reaches junior high/ } \\
\text { middle school, s/he will }\end{array}$ & Mean $(S D)$ & $N$ \\
\hline 1. Be more concerned about his/her appearance & $5.78(1.13)$ & 1260 \\
2. Become more involved in social activities & $5.41(1.11)$ & 1259 \\
3. Take on more responsibilities & $5.35(1.07)$ & 1258 \\
4. Socialize more with members of the opposite sex & $5.15(1.29)$ & 1255 \\
5. Be more concerned with what his/her friends think & & \\
than what I think & $4.94(1.53)$ & 1258 \\
6. Take school work more seriously & $4.70(1.35)$ & 1256 \\
7. Seek my advice more often & $4.07(1.39)$ & 1256 \\
8. Be closer to me because we can share more adult in- & & \\
terests & $3.92(1.48)$ & 1253 \\
9. Be more difficult to get along with & $3.89(1.67)$ & 1258 \\
10. Be less interested in school & $2.70(1.50)$ & 1259 \\
11. Be clumsier & $2.55(1.50)$ & 1255 \\
\hline
\end{tabular}




\section{Analyses}

In order to examine which beliefs and expectations were endorsed most by parents, and to assess the strength of consensus among parents of early adolescent children, means and variances were calculated for individual items. Multivariate analyses of variance (MANOVA) with repeated measures (using SPSS-X) were used to assess the effects of the between-subject factors of parent experience and child sex, and the within-subject factor of parent sex (since mother-father pairs were responding for the same target child, ratings were not considered independent) on target- and category-based beliefs. Given the newly created measure, we chose to use MANOVAs in order to examine differences on individual items as well as on groups of related items. Significant MANOVA effects were further investigated using univariate $t$ and $F$ tests. The $F$ test for homogeneity of variance was used to examine the hypothesis that experience would increase response variance. In addition, repeated measures analysis of variance was used to assess the interaction of experience with belief type (category vs. target based).

\section{Results}

\section{Factor Analysis of Belief Items}

Factor analysis of the nine category-based beliefs did not yield a clear factor structure. Because of the face validity of the factors that emerged among teachers in Study 1, and for ease of comparison across studies, parallel sets of items were used for multivariate analyses: beliefs about a difficult adolescence and beliefs that adults can have an influence. Separate multivariate analyses were run for each set.

Factor analysis, using an oblique rotation, of the eleven target-based items produced three meaningful factors that were the same for mothers and fathers. Items and their loadings for each factor can be found in Table IV. The first factor consisted of four items indicating expectations of increased social involvement, the second consisted of two items tapping expectations for a closer relationship between child and parent, and the third consisted of three items measuring expectations for a difficult adolescence. Separate multivariate analyses were run for these three groups of items. The two items concerned with expectations for school interest and involvement did not load consistently or meaningfully on any factor; thus they were excluded from multivariate analyses. 
Table IV. Parent Target-Based Beliefs: Items, Factor Loadings, and Reliability

Factor I: Social involvement, alpha $=.61$

.43 My child will take on more responsibilities.

.57 My child will be more concerned about his/her appearance.

.67 My child will become more involved in social activities.

.48 My child will socialize more with members of the opposite sex.

Factor 2: Relationship with parents, alpha $=.72$

.64 My child will be closer to me because we can share more adult interests.

.86 My child will seek my advice more often.

Factor 3: Difficulty, alpha $=.56$

.63 My child will be more difficult to get along with.

.43 My child will be clumsier.

.58 My child will be more concerned with what his/her friends think than what I think.

\section{Category-Based Beliefs About Adolescence}

The means and standard deviations for the specific items are presented in Table I. Multivariate analyses indicated that there were significant differences among the items $(F[8,1209]=473.11, p=.000)$. For parents, the highest mean was for Item 1 on Table I, indicating that parents felt there are things they can do to make their relationship with their adolescent good. Parents also thought junior high schools and junior high teachers could have a powerful influence on adolescents (Items 2 and 5). In contrast, and as predicted, they also endorsed the belief that adolescence is a difficult time (Item 3). And like the teachers, they endorsed hormonal causes of this difficulty (Item 4) more highly than physical or social causes (Items 6, 8, and 9). Thus, like teachers, parents tend to endorse the storm and stress stereotype of adolescence as well as the belief that adults can influence development during this period. However, as with the teacher composites, the correlation between composites reflecting the two sets of beliefs was marginally significant but quite low $(r=.08, p=.05)$, suggesting that parents generally do not hold both of these beliefs simultaneously.

To test the effects of parent sex, child sex, and parent experience using multivariate analysis, items were grouped into sets that paralleled composites used with teachers in Study 1: beliefs about a difficult adolescence and beliefs about adult influence.

Parent Sex. Mothers were more likely than fathers to endorse the set of beliefs comprising the "adolescence is a difficult time" factor $\left(M_{\mathrm{m}}=\right.$ $4.65, S D=.88 ; M_{\mathrm{f}}=4.47, S D=.84 ; F[1,598]=15.30, p=.000$ ). 
There was also a significant interaction of parent sex and item $(F[4,595]=$ 13.30, $p=.000$ ). Table $\mathrm{V}$ gives the means and standard deviations on individual category-based items for mothers and fathers. Paired $t$ tests revealed that mothers were more likely than fathers to endorse the following items: "the most sensible approach to adolescence is to relax and realize that in time things will get better" $(t[601]=5.75, p=.000)$, "hormones make early adolescence a difficult time" $(t[601]=5.07, p=.000)$, and "changes in behavior are mainly due to physical changes that are occurring" ( $t[601]$ $=2.71, p=.007$ ).

Table V. Category-Based Beliefs of Mothers and Fathers: Means and Standard Deviations

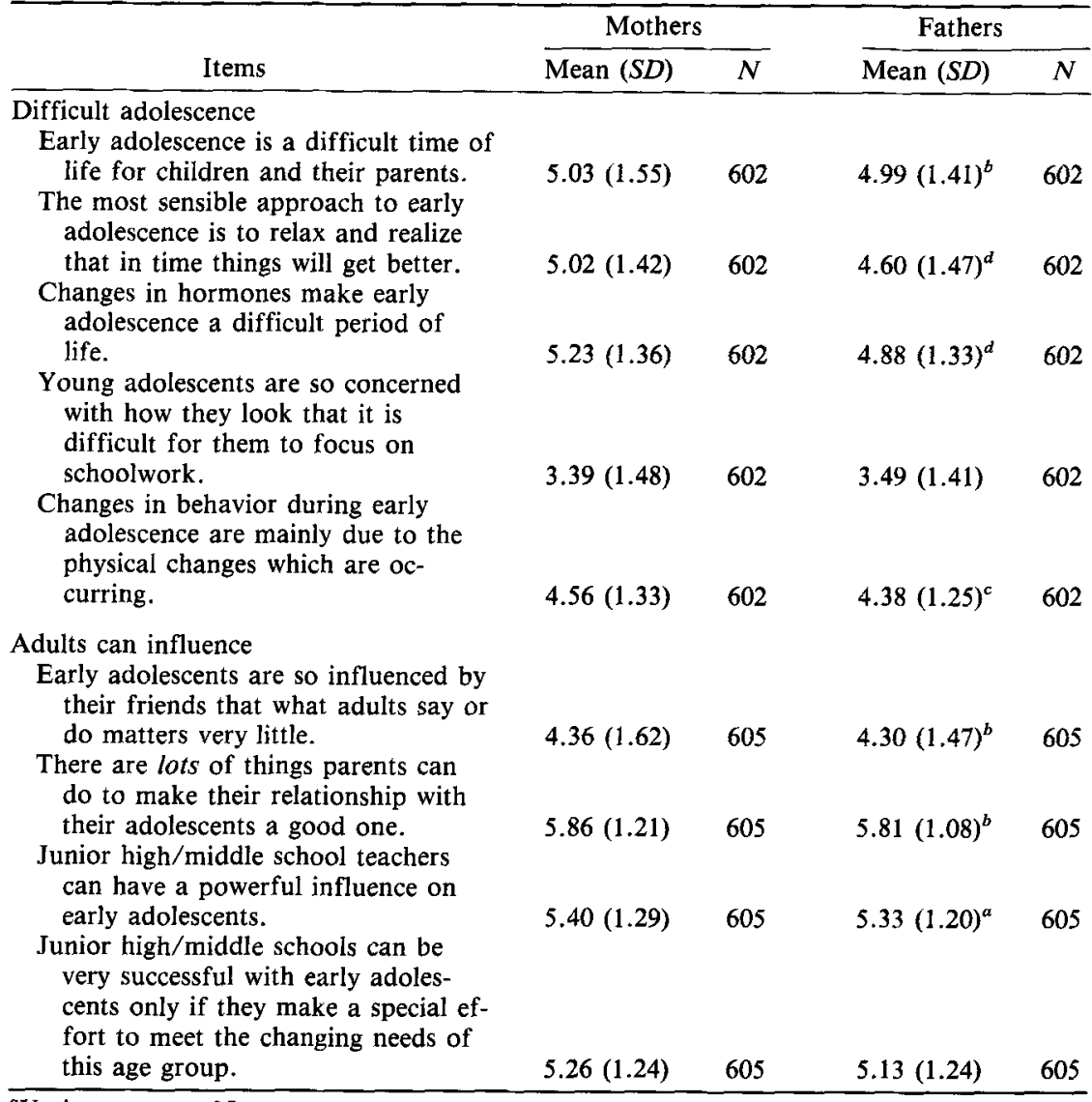

${ }^{a}$ Variance: $p \leq .05$.

${ }^{b}$ Variance: $p \leq .01$.

${ }^{c}$ Mean: $p \leq .01$.

${ }^{d}$ Mean: $p \leq .0001$. 
There were no differences between mothers and fathers in their beliefs about the effectiveness of adults, either as a main effect or as a part of a sex by item interaction.

In line with our predictions, mothers were more variable than fathers on four of the nine items. These included "early adolescence is a difficult time of life $(F[602,602]=6.14, p=01)$, "adolescents are so influenced by friends that what adults say or do matters very little" $(F[605,605]=7.45$, $p<.01$ ), "there are lots of things adults can do to make their relationships with their adolescents good" $(F[605,605]=6.11, p=.01)$, and "teachers can have a powerful influence on early adolescents" $(F[605,605]=4.01, p$ $<.05$ ). In no case were fathers' scores significantly more variable than mothers'.

Amount of Experience. As predicted, there were no differences between groups of parents having different amounts of experience with adolescents for category-based beliefs concerning a difficult adolescence or the ability of adults to help.

Contrary to our predictions, parents' experience affected the variance on only one category-based item: "there are lots of things parents can do to make their relationship with their adolescent a good one" $(F[484,726]=$ $3.77, p=.05)$. Again contrary to our predictions, it was the inexperienced parents who showed more variance on this item.

Child Sex. Multivariate analyses yielded a significant main effect of child sex on the difficult adolescence set $(F[1,598]=10.34, p=.001)$. See Table VI for means and standards deviations on individual items for par-

Table VI. Category-Based Beliefs of Parents of Girls and Boys: Means and Standard Deviations

\begin{tabular}{|c|c|c|c|c|}
\hline \multirow[b]{2}{*}{ Items } & \multicolumn{2}{|c|}{ Parents of girls } & \multicolumn{2}{|c|}{ Parents of boys } \\
\hline & Mean $(S D)$ & $N$ & Mean $(S D)$ & $N$ \\
\hline $\begin{array}{l}\text { Early adolescence is a difficult time of } \\
\text { life for children and their parents. }\end{array}$ & $5.15(1.44)$ & 542 & $4.89(1.49)^{b}$ & 662 \\
\hline $\begin{array}{l}\text { The most sensible approach to early } \\
\text { adolescence is to relax and realize that } \\
\text { in time things will get better. }\end{array}$ & $4.83(1.51)$ & 542 & $4.79(1.42)$ & 662 \\
\hline Changes in hormones make early adoles- & $5.26(1.37)$ & 542 & $4.89(1.32)^{c}$ & 662 \\
\hline $\begin{array}{l}\text { Young adolescents are so concerned with } \\
\text { how they look that it is difficult for } \\
\text { them to focus on schoolwork. }\end{array}$ & $3.56(1.46)$ & 542 & $3.35(1.43)^{a}$ & 662 \\
\hline $\begin{array}{l}\text { Changes in behavior during early adoles- } \\
\text { cence are mainly due to the physical } \\
\text { changes which are occurring. }\end{array}$ & $4.48(1.31)$ & 542 & $4.47(1.27)$ & 662 \\
\hline
\end{tabular}

Mean: $p \leq .05$.

${ }^{b}$ Mean: $p \leq .01$.

${ }^{c}$ Mean: $p \leq .0001$. 
ents of girls and parents of boys. As predicted, parents of daughters endorsed the belief that early adolescence was difficult $(M=4.66, S D=.71)$ more highly than parents of sons $(M=4.48, S D=.67)$. There was also a significant interaction of child sex and item $(F[4,595]=3.43, p=.009)$. Followup univariate analyses indicated that parents of daughters endorsed the following items significantly more highly than parents of sons: "early adolescence is a difficult time" $(F[1,1202]=8.91, p=.003)$, "changes in hormones make early adolescence a difficult period of life" $(F[1,1202]=23.76, p=$ .000 ), and "young adolescents are so concerned with how they look that it is difficult for them to focus on schoolwork" $(F[1,1202]=6.08, p=.02)$. There were no differences by child sex on the "adults can help" cluster of items.

\section{Target-Based Beliefs: Expectations for One's Child}

The means and standard deviations for the items tapping parents' expectations for their own children as they enter junior high school are illustrated in Table III. Multivariate analyses revealed significant differences across item means $(F[8,1227]=499.88, p=.000)$. In general, parents endorsed positive expectations for their children to a greater extent than negative expectations. For example, they endorsed the beliefs that their child will take on more responsibilities and be more serious about schoolwork to a greater extent than they endorsed such negative expectations as $s /$ he will be more difficult to get along with, $s /$ he will be clumsier, and s/he will be less interested in schoolwork. Parents also expected an increase in social and heterosexual interests.

Correlations between composites reflecting the three sets of items were moderate and significant $(p<.01)$ : the social involvement composite and relationship with parents composite correlated .25; the social involvement composite and expectations for difficulty composite correlated .19; the relationship with parents composite, and the expectations for difficulty composite correlated -.14 . To test the effects of sex of parent, sex of child, and experience of parent using multivariate analysis, items were grouped into the three factors summarized in Table IV.

Parent Sex. There was no main effect of parent sex on the social involvement cluster, but there was a significant sex by item interaction $(F[3,612]$ $=9.29, p=.000$ ). See Table VII for means and standard deviations on individual items by parent sex. Paired $t$ tests revealed that mothers were more likely to expect that their adolescent would be more concerned with appearance $(t[617]=2.60, p=.01)$ while fathers were more likely to expect that their adolescent would socialize more with the opposite $\operatorname{sex}(t[617]=-4.31$, $p=.000)$. 
Table VII. Target-Based Beliefs of Mothers and Fathers: Means and Standard Deviations

\begin{tabular}{llllll}
\hline & \multicolumn{2}{c}{ Mothers } & & \multicolumn{2}{c}{ Fathers } \\
& Mean $(S D)$ & $N$ & & Mean $(S D)$ & $N$ \\
\hline $\begin{array}{l}\text { Social involvement } \\
\quad\end{array}$ & $5.32(1.08)$ & 618 & & $5.40(1.07)$ & 618 \\
$\begin{array}{l}\text { Take on more responsibilities } \\
\text { Be more concerned about his/her ap- } \\
\quad \text { pearance }\end{array}$ & $5.84(1.10)$ & 618 & & $5.69(1.16)^{b}$ & 618 \\
$\begin{array}{l}\text { Become more involved in social ac- } \\
\text { tivities }\end{array}$ & $5.41(1.13)$ & 618 & & $5.41(1.09)$ & 618 \\
$\quad \begin{array}{l}\text { Socialize more with members of the } \\
\quad \text { opposite sex }\end{array}$ & $5.01(1.34)$ & 618 & & $5.29(1.22)^{c . d}$ & 618 \\
$\begin{array}{l}\text { Difficulty } \\
\quad \text { Be more difficult to get along with }\end{array}$ & $4.03(1.69)$ & 615 & & $3.74(1.65)^{c}$ & 615 \\
$\quad \begin{array}{l}\text { Be clumsier } \\
\text { Be more concerned with what his/her } \\
\text { friends think than what I think }\end{array}$ & $2.57(1.54)$ & 615 & & $2.55(1.46)$ & 615 \\
\hline
\end{tabular}

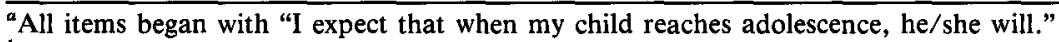

${ }^{b}$ Mean: $p \leq .01$.

${ }^{c}$ Mean: $p \leq .0001$.

${ }^{d}$ Variance: $p \leq .05$.

There was a main effect for parent sex on the set of items comprising the relationship to parent construct $(F[1,612]=12.15, p=.001)$ and no interaction involving items. Fathers $(M=4.11, S D=1.24)$ were more likely than mothers $(M=3.89, S D=1.29)$ to expect that they would have a closer relationship with their child as the child entered adolescence. In addition, there was a significant interaction of parent and child sex $(F[1,612)$ $=17.54, p=.000$ ) showing that mothers expected to become closer to daughters $(M=4.06, S D=1.29)$ than sons $(M=3.75, S D=1.27)$, and fathers expected to become closer to sons $(M=4.24, S D=1.27)$ than daughters $(M=3.96, S D=1.26)$. A three-way interaction of parent sex, child sex, and item $(F[1,612]=14.09, p=.000)$ resulted from the fact that the parent sex by child sex interaction was somewhat stronger for "my child will be closer to me" $(F[1,615]=28.47, p=.000)$ than for "my child will seek my advice more often" $(F[1,616]=4.01, p=.05)$.

A significant main effect of parent sex on the difficult adolescence set of items emerged $(F[1,611]=18.41, p=.000)$. Mothers were more likely to expect difficulty from their children than fathers $\left(M_{\mathrm{m}}=3.90, S D=\right.$ $\left.1.17 ; M_{\mathrm{f}}=3.68, S D=1.11\right)$. There was also a significant interaction of parent sex and item $(F[2,610]=5.71, p=.003)$. Mothers were more likely than fathers to say that their adolescent would be difficult to get along with $(t[615]=3.86, p=.0001)$, and more concerned with what friends think than what parents think $(t[615]=4.85, p=.000)$. 
In only one case did mothers show more variance than fathers on the target-based items. Mothers were more variable in their expectations that their adolescent would socialize more with the opposite $\operatorname{sex}(F[618,618]=$ 5.44, $p<.02$ ).

Amount of Experience. There were no effects of amount of experience on the social involvement set. There were, however, significant effects of experience on the relationship with parents items $(F[1,612]=7.79, p=.005)$ and on the difficult adolescence items $(F[1,611]=4.54, p=.03)$. On the one hand, inexperienced parents had higher expectations that their child would get closer to them in adolescence than experienced parents $\left(M_{\text {inexp }}=4.13\right.$, $\left.S D=.97 ; M_{\exp }=3.91, S D=1.00\right)$. On the other hand, they were more likely to expect that things would get more difficult when their children entered adolescence $\left(M_{\text {inexp }}=3.89, S D=.93 ; M_{\text {exp }}=3.73, S D=.95\right)$.

In addition, as predicted, experienced parents were significantly more variable in their responses to four of the target-based items. More variability occurred with regard to more concern with appearance $(F[498,738]=$ $20.53, p=.000)$, more involvement with social activities $(F[498,738]=9.07$, $p=.003)$, more socialization with the opposite $\operatorname{sex}(F[498,738]=10.49$, $p=.001)$, and more concern with friends than parents $(F[498,738]=4.49$, $p=.03$ ).

Child Sex. There was no main effect of child sex for the social involvement set; however, there was a significant interaction of child sex and item $(F[3,612]=4.82, p=.003)$. Parents expected that daughters $(M=5.53$, $S D=1.06, N=568)$ would become more involved than sons $(M=5.31$, $S D=1.14, N=668)$ in social activities $(F[1,1250]=12.17, p=.0005)$.

There were no effects of child sex on expectations for the adolescent's relationship with parents other than the interaction reported above (mothers expect to be closer to daughters and fathers expect to be closer to sons). There were also no effects of child sex on the difficult adolescence set.

\section{Category-Based vs. Target-Based Beliefs}

In order to see if there was an overall difference in endorsement of category- and target-based beliefs, a repeated measures analysis of variance was used. The dependent variables were composites representing the mean of all category-based items and all target-based items; items were entered into the composites with the more stereotyped response as the high score. The repeated measure was type of belief, and the between-subjects factors were sex of parent, sex of child, and amount of experience. Main effects of parent $\operatorname{sex}(F[1,1193]=12.37, p=.000)$ and child $\operatorname{sex}(F[1,1193]=4.33$, $p=.04)$ indicated that mothers were more likely to endorse category- and 


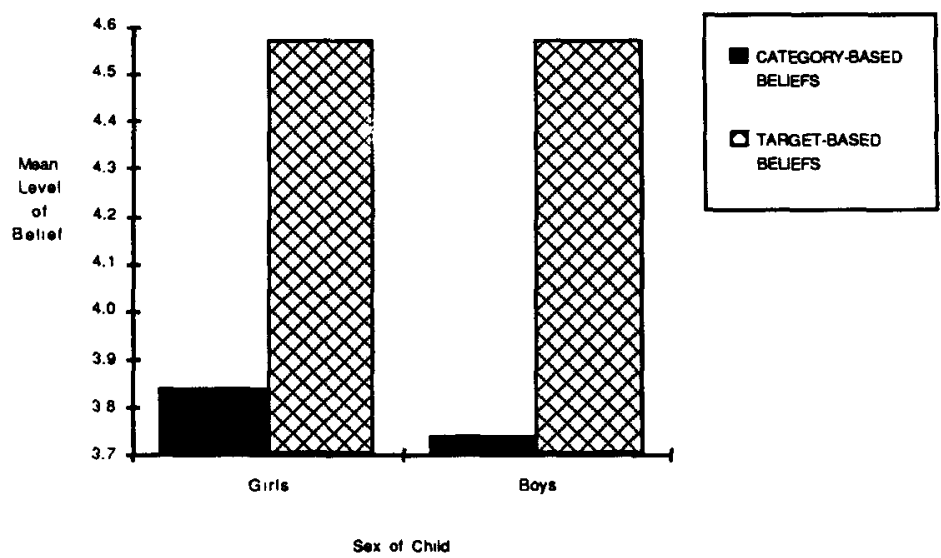

Fig. 1. The effect of child sex on parents' category- and target-based beliefs about adolescence. (Higher mean level of belief is more stereotyped.)

target-based beliefs in accordance with stereotypes than fathers, and that stereotypes were more prevalent for daughters than sons.

There was a significant difference in overall endorsement of categoryand target-based beliefs $(F[1,1193]=1146.39, p=.000)$; contrary to our predictions, target-based beliefs were endorsed at a higher level $(M=4.57$, $S D=.62)$ than category-based beliefs $(M=3.78, S D=.56)$. The only interaction that reached significance was the child sex by type of belief interaction $(F[1,1193]=3.99, p=.05$; see Fig. 1). Although category-based beliefs were endorsed less than target-based beliefs by parents of both sexes, the difference was greater for boys. The interactions between sex or experience of parent and type of belief were not significant; thus contrary to our prediction, experiential differences were no greater on target-based than categorybased beliefs.

Contrary to our predictions, differences in variability between mothers and fathers were more common on category-based beliefs (four out of nine) than on target-based beliefs (one out of nine). As predicted, however, more experienced parents showed more variability on four of nine target-based items, and no more variability on category-based items. On the one categorybased item where there was a difference in variance, less experienced parents were more variable. 


\section{STUDY 3: TEACHERS AND PARENTS COMPARED - THE EFFECT OF EXPERIENCE ON CATEGORY-BASED BELIEFS}

In order to assess whether amount of experience had more of an effect on the category-based beliefs of teachers than those of parents, repeated measures analyses of variance were performed with composites of the two category-based beliefs (difficult time and adults can help) as dependent variables, and the subject group (teachers from Study 1 and parents from Study 2 ) as the grouping variable. Teacher items were converted from 5-point to 7-point scales for comparability of analysis. A three-way interaction between subject group, experience, and belief $(F[1,1310]=5.12, p=.02$; see Fig. 2 ) indicated that the difference between teachers of high and low experience in their endorsement of "adolescence is a difficult time" was significantly greater than the difference found between more and less experienced parents. Contrary to our hypothesis, experience in teachers was related to more (rather than less) stereotyped beliefs regarding difficulty; among parents this relationship did not exist.

There were no significant interactions between sex and subject group, indicating that although more sex differences were found in the parent sample than in the teacher sample on category-based beliefs when these samples were analyzed separately, overall the effect of sex on these beliefs was not different for parents and teachers.

\section{DISCUSSION}

\section{What Parents and Teachers Believe}

\section{Developmental Optimists or Developmental Pessimists?}

What do parents and teachers of early adolescent children believe about adolescence as a developmental period? As predicted, teachers and parents hold both positive and negative category-based beliefs about adolescent development. On the one hand, they believe adolescence is a difficult time of life and that hormones make it difficult; on the other hand, they believe adults can make a difference. Consistent with these beliefs, they are also not likely to think that friends are so important to adolescents that what adults say or do matters little. Similar results were characteristic of target-based expectations. Parents as a group indicate that they expect that their children will develop increasing social interests, but not necessarily at the expense of school or relationships with parents. 


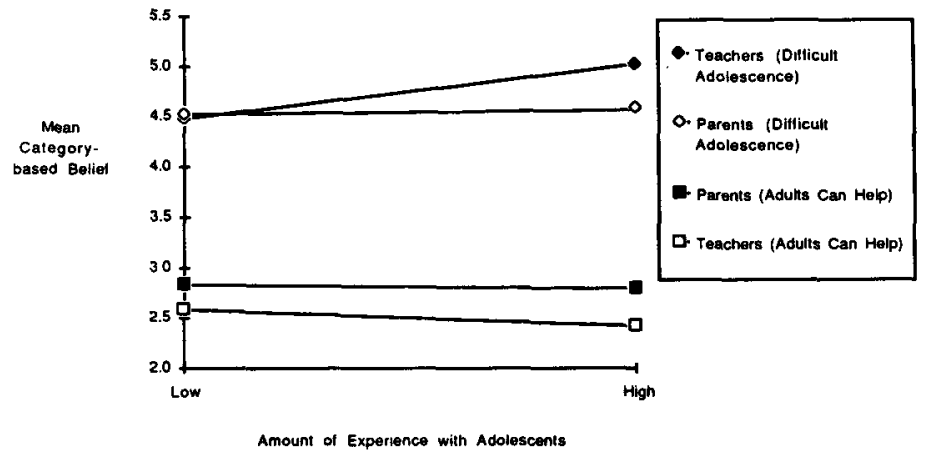

Fig. 2. The effect of amount of experience on the category-based beliefs of teachers and parents. (Higher mean level of belief is more stereotyped.)

Do these results indicate, however, that parents are "developmental optimists"? Not necessarily, especially if we mean by "developmental optimists" that parents believe in their ability to influence their children's development despite expectations that adolescence is a difficult time. If individual teachers and parents believed both in difficulty and in positive developments, significant positive correlations between the two types of beliefs should have emerged; they did not. The low correlations between positive and negative items and composites indicates that the positive and negative beliefs are independent of one another, and do not typically coexist in the same teachers and parents. The data reported here support the notion of developmental optimism in the sense that many adults endorse fairly strongly the belief that adults can make a difference during adolescence and in the sense that the adults are not "developmental pessimists": i.e., there is not a strong negative correlation between the positive and negative beliefs.

In general, then, although parents and teachers believe some negative developments occur at adolescence, they are by no means developmental pessimists. Even though individual adults may not strongly endorse both negative and positive items, they also do not think that negative developments mitigate against positive outcomes. And they do not feel helpless in the face of change, although they do tend to think that "relaxing and waiting" is a good response during this period. These data demonstrate the importance of questioning adults about both positive and negative developments of the period, since by inquiring only about negative impressions, one may be led to believe erroneously that adults hold primarily pessimistic views of adolescence. 


\section{Category-Based vs. Target-Based Beliefs}

Data from the parents in Study 2 did not support the prediction that category-based beliefs would be endorsed more strongly than target-based beliefs. Instead, stereotyped target-based beliefs were endorsed significantly more than category-based beliefs. Perhaps parents are particularly aware of and concerned about their own children's development, and rather than seeing exceptions to stereotypes, find "kernels of truth" in their own children's behavior that confirm the stereotypes. This issue will be discussed at greater length later in this discussion.

\section{Adult Sex Differences}

Do the different roles that mothers and fathers play in the life of an adolescent lead to different category- or target-based beliefs? Existing research and theory suggest opposing hypotheses regarding the mean levels of mothers' vs. fathers' beliefs. Although the greater time mothers spend with children could lead to less stereotyping, the particular quality of their role could make them more sensitive to problems and conflict, leading to more stereotyping. Given the differences in time spent with one's children, we did predict that mothers would be more variable in their beliefs. To the extent that it is experience that accounts for variance differences, we predicted that any differences that emerged would be greater for target-based beliefs than category-based beliefs since target-based beliefs should be more susceptible to the influence of experience.

\section{Mean Differences: Category-Based Beliefs}

Our data suggest that mothers are more likely than fathers to think that adolescence is a difficult time, and that biological and maturational changes contribute to this difficulty. Mothers believed, more than fathers, that hormones and physical changes make adolescence difficult. Given these views, it is interesting that mothers were also more likely than fathers to believe the best approach to adolescence is to relax and wait it out, a view consistent with a stage, or maturational, orientation to development. Despite this laissez faire orientation, mothers do not feel less efficacious than fathers, as shown by the fact that they are equally likely to endorse the set of items measuring confidence in adults' ability to help.

The emphasis on the physiological bases for difficulty by mothers may result from their own experiences with both puberty and other biological/developmental processes. For females, the physical changes of puberty are more 
obvious and often bothersome, and may remain more salient across the life span. Consistent with this view, feminist social scientists and philosophers have argued that females may be more in tune with biological and developmental rhythms. (However, this notion conflicts with some data suggesting that males have more stereotyped notions about the physical and psychological effects of menstruation [Brooks-Gunn and Ruble, 1986; Ruble et al., 1982].)

\section{Mean Differences: Target-Based Beliefs}

As with category-based beliefs, mothers were more concerned than fathers with potential difficulty: they anticipated more conflict for their adolescents between what friends think and what adults think, and feared more that their adolescent would become more difficult to get along with than did fathers. Mothers were also more apt to expect that their children would become more concerned with appearance. Fathers, on the other hand, expected their children, sons in particular, to become closer to them and seek their advice more often. They also expected their children to become increasingly interested in the opposite sex.

In general, then, we do not find support for mothers being less stereotyped than fathers on either category-based or target-based beliefs. Instead, our data suggest that mothers are indeed more sensitive to difficulties they perceive to be associated with adolescence, including the hardships of adjusting to physical changes and increasing conflict between parent and peer pressures. Contrary to our hypothesis, this was equally true for categoryand target-based beliefs.

This pattern of adult sex differences is consistent with the different roles mothers and fathers play (Hill and Holmbeck, 1987a; Youniss and Smollar, 1985), and with what others have found concerning differences in parent-child relationships at adolescence, e.g., that more conflict exists between adolescents and mothers than between adolescents and fathers (Montemayor, 1982; Montemayor and Hanson, 1985; Steinberg, 1987). Thus, even if conflict with adolescents is not as great as is stereotypically believed, the conflict that does occur is more likely to occur between adolescents and mothers, and may be very salient to the individuals in the family even though it is relatively low in level (cf. Hill and Holmbeck, 1987b). Together with the fact that mothers may be more sensitive to any difficulties that occur (Collins et al., 1987) and more likely to interpret conflict as oppositionalism (Hill and Holmbeck, 1987a), mothers' heightened endorsement of difficulty can be understood.

A significant interaction between parent and child sex concerning parents' expectations for their relationships with their adolescents indicated that mothers expected to become closer to daughters than sons and fathers ex- 
pected to become closer to sons than daughters. Expectations for increased closeness with same-sex children may suggest that parents see more similarities between themselves and same-sex children (in contrast to opposite-sex children). Parents may, as a result, begin to initiate more activities or communication with same-sex children as children enter adolescence. To the extent that parents engage in gender role stereotyped activities, increases in the frequency of interaction in those stereotyped activities could contribute to the gender intensification phenomenon discussed by Hill and Lynch (1983).

\section{Variance Differences}

The impact of experience on responses can also be assessed through its impact on the variability of responses in groups with different levels or types of experience. If so, then mothers, due to the fact that they spend more time with their children, and due to their more intimate and individual experiences with their children, should be more variable than fathers in their responses, especially to target-based items. We found partial, but not strong, support for this prediction. In all five instances where there were significant differences in variability in Study 2, mothers were more variable; however, four of these differences occurred on category-based items. Thus, in support of our prediction, it does seem that mothers tend to be more variable in their responses than fathers, but the difference is found for both categoryand target-based items.

\section{"Experience with Other Adolescent" Differences}

\section{Mean Differences Among Parents: Category-and Target-Based Beliefs}

We predicted that parents who had previous experience with at least one adolescent in the home would hold less stereotyped beliefs about adolescents and therefore be less likely to endorse negative beliefs about this period, especially in regard to their own children. Amount of experience with adolescents among parents made no difference in category-based beliefs about adolescence being a difficult time or about the ability of adults to influence adolescent outcomes.

Experienced parents were less likely than inexperienced parents to expect their own children to become closer to them; however, they were also less likely to expect difficulty. Since target-based beliefs are based on individual children, it may not be possible to predict in advance how experience will modify them. If this is true, experience would not have consistent and predictable effects on the level of belief about particular individuals. Instead, ex- 
perience might induce more variability as we predicted. This hypothesis is discussed in the next section. In contrast, it may be that parents learn a mixture of things from having experience with adolescents. They may come to see that this period of development is not as bad as cultural stereotypes suggest. However, they also may be more aware of the reality that adolescents become more independent, and more involved with activities and peers outside the home; therefore, they may be less idealistic about the increased closeness that a child's growing maturity might be expected to bring.

Unfortunately, in our sample we cannot unconfound parents' experience and parents' age. Thus, we cannot examine the extent to which these differences in beliefs about adolescence might reflect the fact that parents with more experience are from a different cohort, or at a different stage of their adult life, than parents with less experience. Other research indicates that adult attitudes and well-being are related both to age and stage of parenting (Cohen et al., 1986; Feldman et al., 1981; Peskin and Livson, 1981; Rossi, 1980); thus, a task for future research in this area is to clarify the role each might play in parental attitudes toward adolescence.

The lack of a significant interaction between amount of experience and type of belief suggests that, contrary to our hypothesis, the impact of experience is not greater for target-based beliefs than for category-based beliefs as they were measured here.

\section{Mean Differences Among Teachers}

As discussed above, experience had little impact on the category-based beliefs of parents. We had predicted, however, that experience would affect the category-based beliefs of teachers, since teachers interact with adolescents repeatedly, and mostly as a group. In Study 1, experience was in fact related to teachers' category-based beliefs concerning adolescence as a difficult time period. In addition, as predicted, the effect of experience on categorybased beliefs about the difficulty of adolescence was greater for teachers than parents in Study 3. However, the direction of the effect went counter to the prediction that daily experience with adolescents would moderate stereotypical notions. For teachers, the longer one had been teaching, the more likely s/he was to endorse statements suggesting that early adolescence is a difficult stage. As with the parents, we cannot unconfound teacher age with experience; thus these results might reflect cohort or stage of life effects rather than experience effects. Alternatively, there is evidence that other beliefs held by teachers also become more negative and pessimistic with experience (Beady and Hansell, 1981; Brown and Gibson, 1982, Hoy, 1968). Our finding may reflect a general progression toward "burn out" the longer one has been teaching. 
Another possibility is that the culture of the junior high school is such that teachers are socialized by their colleagues into greater endorsement of the cultural stereotype the longer they are in the junior high school, independent of actual characteristics of the students. Attributing one's teaching difficulties to characteristics of the students that are beyond one's control provides a convenient ego-saving explanation for lack of student progress; over time use of this attribution could augment and reinforce one's stereotypic notions regarding children at this stage of life, especially if its use is condoned by one's peer professionals.

Despite the fact that experience had a different effect on category beliefs than originally predicted, we did find the expected interaction between experience and subject group. Experience had an effect on category-based beliefs of teachers and not parents, suggesting that repeated exposure to groups of adolescents may be more likely to lead to changes in general stereotypes than experience with one or two individual adolescents over time.

\section{Variance Differences}

As predicted, parents with more experience gave more variable responses than parents with less experience, and only for target-based items. On category-based beliefs, parents with more experience were less variable on only one item. In contrast, parents with more experience were more variable on four target-based items. There is some evidence, then, that experience has a more consistent impact on the variability of expectancies rather than on their mean levels. The more time and experience one has with adolescents, the more information one has to draw on, other than cultural stereotypes. Parents who have already experienced adolescence with at least one child are more likely to have seen that events during adolescence vary to a large degree depending on individual and circumstances. That the variance differences are somewhat larger and more frequent for expectancies about individuals than they are for general stereotypes suggests that the effect of this experience does not always generalize. Among teachers, experience did not effect variability of category-based beliefs; for possible reasons outlined above, it seems that the experience of teachers strengthens and consolidates stereotypes.

\section{Measurement Issues: What Is a Stereotype?}

The finding that higher levels of exposure to or experience with adolescents (among teachers and, in some cases, among parents) are associated with increased response in a stereotypic direction also raises the issue of measure- 
ment of adults' beliefs and stereotypes. We had assumed that a higher score on a negative item indicated a more stereotypic response. However, it may be that stereotyped responses can only be inferred for the very extreme responses. Since there is likely to be some truth to each of the items, a respondent with a relatively high score may either experience relatively more of that behavior, or may be more willing to endorse that behavior. For example, mothers may indeed experience more conflict with their children than fathers do, leading to their higher concerns about difficulty. Among teachers, those with less experience may have a vested interest in reporting more positive expectations than the stereotype implies. More experienced teachers may have incorporated their exposure to moderate levels of the behaviors under consideration into a culturally stereotyped schema as confirmation of the stereotypic beliefs. The responses of more experienced teachers would thus appear more stereotypic than those of less experienced teachers.

\section{Sex of Child Differences}

As predicted, parents of daughters expressed more beliefs regarding adolescence as a difficult period than parents of sons; contrary to our expectations, the effect of child sex was equally as strong for category-based beliefs and target-based beliefs. The belief of parents of daughters that adolescence is a difficult time and that hormones and concern with appearance contribute to this difficulty, suggests that having a daughter may sensitize parents to the biological changes of the time. Parents of daughters were also more likely than parents of sons to expect their child to become more involved in social activities as $\mathrm{s} / \mathrm{he}$ reached junior high school. Perhaps this reflects a greater parental concern with social involvement, and/or increasingly traditional gender role expectations, thought to be characteristic of parents of girls entering adolescence (Hill et al., 1985; Hill and Lynch, 1983). Alternatively, the girls may simply be more developed pubertally and therefore be expected to become more socially oriented than boys in the next year as a normal consequence of their greater maturity.

\section{Summary}

In summary, data from the studies reported here suggest that both cultural transmission and personal experience influence adults' beliefs about adolescents. The role of cultural transmission is strong, in that stereotyped notions of adolescent difficulty are endorsed fairly consistently by all groups. At the same time, a large number of parents and teachers do not believe themselves to be helpless in the face of that difficulty. 
The effect of personal experience (whether reflected in adult sex or amount of exposure) on adults' beliefs about adolescents is not altogether straightforward, but this initial investigation does suggest avenues for further research. First, the experience of mothers with physical/biological events, the unique perturbations that take place between mothers and their children, and/or the greater sensitivity of mothers to adolescent difficulty seem to lead to stronger beliefs by mothers than fathers in impending difficulty at adolescence. Future research should try to delineate more specifically how each of these aspects of motherhood plays a role in development and modification of beliefs.

Second, we have some evidence that amount of exposure to adolescents is less likely to decrease stereotypes in beliefs than it is to increase variability. Although experience leads one to take into account individual variation as well as culturally determined expectancies in predicting what will happen concerning a particular individual, it does not always seem to make parents' beliefs about adolescence less stereotyped. Whether this is due to the strength of these beliefs despite evidence to the contrary, or to the fact that events in adolescence contain enough real elements confirming these stereotypes, is a question for future investigations. Further studies are needed that control for the actual quality of the experiences of parents and teachers in assessing the direction of the impact of such experiences on their beliefs.

\section{ACKNOWLEDGMENTS}

We gratefully acknowledge the hard work of many people that made possible the studies from which these data are drawn: Bonnie Barber, Elaine Carlson, Janis Jacobs, Douglas MacIver, David Reuman, Allan Wigfield, and Doris Yee.

\section{REFERENCES}

Bandura, A. (1964). The stormy decade: Fact or fiction? Psychology Schools 1: 224-236.

Bandura, A., and Walters, R. H. (1959). Adolescent aggression. Ronald, New York.

Beady, C. H., Jr., and Hansell, S. (1981). Teacher race and expectations for student achievement. Am. Educa. Res. J. 18: 191-206.

Beck, A. L., Adler, N. E., and Irwin, C. E. (1985). A comparison of nurses' attitudes toward hospitalized adolescents and adults. J. Adoles. Health Care 6: 211-215.

Bengtson, V. L. (1970). The generation gap: A review and typology of social-psychological perspectives. Youth Society, 2: 7-32.

Brooks-Gunn, J., and Ruble, D. N. (1986). Men's and women's attitudes and beliefs about the menstrual cycle. Sex Roles 14: 287-299.

Brown, R., and Gibson, S. (1982). Teachers' Sense of Efficacy: Changes Due to Experience. Summary of a presentation at the California Educational Research Association Conference, Sacramento, CA. 
Cohen, M., Adler, N., Beck, A., and Irwin, C. E. (1986). Parental reactions to the onset of adolescence. J. Adoles. Health Care 7: 101-106.

Collins, W. A., Carlton-Ford, S., Gangestad, S., Johnson, B. M., and Schoenleber, K. (1987, April). Parental expectations and emotions in relationships during the transition to adolescence. In Collins, W. A. (chair), Parent Factors in Changing Family Relationships in Adolescence. Symposium presented at the biennial meetings of the Society for Research in Child Development, Baltimore, MD.

Douvan, E., and Adelson, J. (1966). The Adolescent Experience. Wiley, New York.

Dix, T. (1985, April). Parents' beliefs about misconduct: Affect and attribution in socialization. In Goodnow, J. (chair), Parents' Ideas About Development and Parenting. Symposium presented at the biennial meeting of the Society for Research in Child Development, Toronto, Canada.

Eccles, J. S., and Jacobs, J. (1986). Social forces shape math participation. Signs 11: 367-380.

Eccles-Parsons, J. S., Adler, T. F., and Kaczala, C. M. (1982). Socialization of achievement attitudes and beliefs: Parental influences. Child Develop. 53: 310-321.

Elkin, F., and Westley, W. A. (1955). The myth of adolescent culture. Am. Sociol. Rev. 20: 680-684.

Epperson, D. C. (1964). A re-assessment of indices of parental influence in The Adolescent Society. Am. Sociol. Rev. 29: 93-96.

Falchikov, N. (1986). Images of adolescence: An investigation into the accuracy of the image of adolescence as constructed by British newspapers. J. Adoles. 9: 167-180.

Feldman, S. S., and Yirmiya, N. (1986). Perception of socialization roles: A study of Israeli mothers in town and kibbutz. Internat. J. Psychol. 21, 153-165.

Feldman, S. S., Zeynep, C. B., and Nash, S. C. (1981). Fluctuations of sex-related self-attributions as a function of stage of family life cycle. Develop. Psychol. 17: 24-35.

Friedman, R. (1975). The vicissitudes of adolescent development and what it activates in adults. Adolescence 10: 520-526.

Goodnow, J. J. (1984). Parents' ideas about parenting and development: A review of issues and recent work. In Lamb, M., Brown, A., and Rogoff, B. (eds.), Advances in Developmental Psychology. Erlbaum, Hillsdale, NJ.

Goodnow, J. J. (1988). Parents' ideas, actions, and feelings: Models and methods from developmental and social psychology. Child Develop. 59: 286-320.

Goodnow, J., Knight, R., and Cashmore, J. (1986). Adult social cognition: Implications of parents' ideas for approaches to development. In Perlmutter, M. (ed.), Cognitive Perspectives on Children's Social and Behavioral Development, Minnesota Symposia on Child Psychology (Vol. 18). Erlbaum, Hillsdale, NJ.

Goodnow, J. J., Cashmore, J., Cotton, S., and Knight, R. (1981, April). Mothers' developmental timetables and associated ideas. Paper presented at the biennial meeting of the Society for Research in Child Development, Boston, MA.

Goodnow, J. J., Cashmore, J. A., Cotton, S., and Knight, R., (1984). Mothers' developmental timetables in two cultural groups. Internat. J. Psychol. 19: 193-205.

Hill, J. P., and Holmbeck, G. N. (1987a). Disagreements about rules in families with seventhgrade girls and boys. J. Youth Adoles. 16: 221-246.

Hill, J. P., and Holmbeck, G. N. (1987b). Familial adaptation to biological change during adolescence. In Lerner, R. M., and Foch, T. T. (eds.), Biological-Psychosocial Interactions in Early Adolescence. Erlbaum, Hillsdale, NJ.

Hill, J. P., and Lynch, M. E. (1983). The intensification of gender-related role expectations during early adolescence. In Brooks-Gunn, J., and Petersen, A. C. (eds.), Girls at Puberty: Biological and Psychosocial Perspectives. Plenum Press, New York.

Hill, J. P., Holmbeck, G. N., Marlow, L., Green, T. M., and Lynch, M. E. (1985). Menarcheal status and parent-child relations in families of seventh-grade girls. J. Youth Adoles, 14: 301-316.

Holmbeck, G. N., and Hill, J. P. (1988). Storm and stress beliefs about adolescence: Prevalence, self-reported antecedents, and effects of an undergraduate course. J. Youth Adoles. 17: $285-306$.

Hoy, W. K. (1968). The influence of experience on the beginning teacher. School Rev. 76: 312-323.

Jacobs, J. (1986). Parents' gender stereotypes and perceptions of their child's abilities: Influences on the child. Unpublished doctoral dissertation, The University of Michigan, Ann Arbor. 
Knight, R. A. (1985, April). Parents as developmental optimists. Paper presented at the biennial meeting of the Society for Research in Child Development, Toronto, Canada.

Lamb, M. E. (1981). The role of the father in child development (rev. ed.). Wiley, New York.

Lavigne, J. V. (1977). The pediatric hospital staff's knowledge of normal adolescent development. J. Pediat. Psychol. 2: 98-100.

Montemayor, R. (1982). The relationship between parent-adolescent conflict and the amount of time adolescents spend alone and with parents and peers. Child Devleop. 53: 1512-1519.

Montemayor, R. (1983). Parents and adolescents in conflict: All families some of the time and some families all of the time. J. Early Adoles. 3: 83-103.

Montemayor, R. (1986). Family variation in parent-adolescent storm and stress. J. Adoles. Res. 1: $15-31$.

Montemayor, R., and Hanson, E. (1985). A naturalistic view of conflict between adolescents and their parents and siblings. J. Early Adoles. 5: 23-30.

Offer, D. (1969). The Psychological World of the Teen-Ager: A Study of Normal Adolescent Boys. Basic Books, New York.

Offer, D., Ostrov, E., and Howard, K. I. (1981). The mental health professional's concept of the normal adolescent. Arch. Gen. Psychiat. 38: 149-153.

Peskin, H., and Livson, N. (1981). Uses of the past in adult psychological health. In Eichorn, D. H., Clausen, J. A., Haan, N., Honzik, M. P., and Mussen, P. H. (eds.), Present and Past in Middle Life. Academic Press, New York.

Petersen, A. C. (1985). Pubertal development as a cause of disturbance: Myths, realities, and unanswered questions. Genet. Social Gen. Psychol. Monogr. 111: 205-232.

Porteous, M. A., and Colston, N. J. (1980). How adolescents are reported in the British press. J. Adoles. 3: 197-207.

Rossi, A. S. (1980). Aging and parenthood in the middle years. In Baltes, P. B., and Brim, O. G. (eds.), Life-Span Development and Behavior. Academic Press, New York.

Ruble, D. N., Boggiano, A., and Brooks-Gunn, J. (1982). Men's and women's evaluations of menstrual-related excuses. Sex Roles 8: 625-638.

Rutter, M., Graham, P., Chadwick, O. F. D., and Yule, W. (1976). Adolescent turmoil: Fact or fiction? J. Child Psychol. Psychiatr. 17: 35-56.

Steinberg, L. (1987). The impact of puberty on family relations: Effects of pubertal status and pubertal timing. Develop. Psychol. 23: 451-460.

Teen rage. (1987, March 19). Detroit Free Press, p. 1B.

Timmer, S. G., Eccles, J., and O'Brien, K. (1985). How children use time. In Juster, T., and Stafford, F. P. (eds.), Time, Goods, and Well Being. Institute for Social Research Press, The University of Michigan, Ann Arbor.

Youniss, J., and Smollar, J. (1985). Adolescent Relations with Mothers, Fathers, and Friends. University of Chicago Press, Chicago. 